\title{
Nomophobia dan Kepribadian Siswa SMA
}

\author{
Chintia Aurelia' ${ }^{1}$, Yuninda Tria Ningsih ${ }^{1}$ \\ 1Fakultas Psikologi dan Kesehatan Universitas Negeri Padang
}

DOI: http://doi.org/10.29080/jpp.v12i2.635

\begin{abstract}
Nomophobia is an irrational fear of not being able to reach their smartphones or communicate through their mobile devices. This research aims to study the nomophobia in terms of personality. Having comparative quantitative study, there are 320 high school students who have smartphones in Bukittinggi were involved. Sampling technique used is proportional sampling which covering 117 male students and 203 female students. Data was collected using a nomophobia scale and big five personality scale adapted from the IPIP (International Personality Item Pool). Having analyzed using one-way ANOVA test, the result show that there are differences in nomophobia in terms of the big five personality among high school students in Bukittinggi.
\end{abstract}

Keyword : nomophobia, big five personality, smartphone, high school students

\begin{abstract}
Abstrak : Nomophobia adalah ketakutan irasional pada individu yang tidak dapat menjangkau smartphone atau berkomunikasi melalui perangkat seluler miliknya. Penelitian kuantitatif komparasi ini melibatkan 320 siswa SMA yang memiliki smartphone di Kota Bukittinggi. Teknik sampling yang digunakan adalah proposional yang terdiri dari 117 siswa laki-laki dan 203 perempuan. Pengambilan data ini menggunakan skala nomophobia disusun oleh peneliti sendiri dan skala kepribadian big five IPIP-BFM-50 yang diadaptasi dari IPIP (International Personality Item Pool). Hasil analisis data menggunakan uji beda anava satu jalur menunjukkan terdapat perbedaan kecenderungan nomophobia ditinjau dari big five personality pada siswa SMA di Kota Bukittinggi.
\end{abstract}

Kata kunci : nomophobia, big five personality, smartphone, siswa SMA

\section{Pendahuluan}

Nomophobia adalah penggunaan secara berlebihan hingga tidak bisa lepas dari smartphone (Yildirirm, 2014). Nomophobia atau no-mobile-phone-phobia diartikan juga sebagai ketakutan irasional yang terjadi ketika seseorang tidak dapat menjangkau smartphone atau berkomunikasi melalui perangkat seluler miliknya (King, Valenca, \& Nardi 2010). Meskipun hingga saat ini nomophobia belum terdaftar pada DSM-V, banyak penelitian yang menyebutkan nomophobia adalah bagian dari agoraphobia (King et al., 2010; King et al., 2013; Yildirirm, 2014; Bragazzi \& Puente, 2014). Kecenderungan nomophobia dapat mempengaruhi berbagai aspek kehidupan yaitu

Corresponding Author: Chintia Aurelia (e-mail: chintiaaurelia18@gmail.com) Fakultas Psikologi dan Kesehatan Universitas Negeri Padang, Jl. Prof. Dr. Hamka, Air Tawar Padang, Sumatera Barat, Indonesia 
psikologis, fisik, relasi sosiail, perilaku, pekerjaan, hingga dapat berurusan dengan hukum (Yuwanto, 2010).

Idealnya penggunaan smartphone memberikan banyak dampak positif bagi penggunanya, namun apabila penggunaanya terlalu berlebihan dapat mengganggu produktivitas individu dan menyebabkan kurang optimal dalam melakukan berbagai kegiatan (Aggarwal, Basu, \& Grover, 2012). Menurunnya prestasi belajar dan keterampilan dalam berperilaku sosial menjadi salah satu dampak dari tidak dapat mengontrol penggunaan smartphone pada remaja (Febriana \& Mariyana, 2020). Nomophobia juga berisiko tinggi mengalami stres, kehilangan konsentrasi, memiliki perasaan kurang bahagia dan intensi bunuh diri (Aggarwal, Basu, \& Grover, 2012). Medical Colage di India menemukan 20\% subjek merasa tidak dapat berkonsentrasi dan menjadi stres ketika tidak dapat mengakses smartphone miliknya pada saat kehabisan daya baterai (Dixit et al., 2010). Penelitian Aljomaa (2016) terhadap 416 remaja juga menunjukan 48\% remaja mengalami perasaan tidak nyaman ketika tidak dapat mengakses smartphone mereka.

Berdasarkan hasil survei data awal yang peneliti sebarkan pada tanggal 3 Januari 2021, siswa SMA di Bukittinggi merasa kesulitan jika jauh dari smartphone. Mayoritas siswa menggunakan smartphone pada saat jam pelajaran di dalam kelas, rapat organisasi, situasi santai maupun formal (Aurelia, 2021). Mereka merasa gelisah ketika kehabisan daya baterai smartphone, kuota internet habis, tidak tersedianya wifi dan panik ketika lupa dimana menyimpan smartphone. Selain itu mereka juga membawa smartphone kemana-mana termasuk saat berkumpul dengan keluarga, makan, tidur, hingga pergi ke toilet. Ketika akan tidur pun mereka meletakan smartphone tidak jauh dari tempat tidur agar mudah dijangkau ketika ada notifikasi berbunyi. Pada umumnya mereka mengecek smartphone sebelum dan setelah bangun tidur, menghabiskan banyak waktu bersama smartphone dengan berbagai tujuan seperti mengambil foto, mengecek pesan singkat, melihat koleksi foto, mengecek laman sosial media, browsing dan online shopping.

Menurut Bianchi dan Phillips (2005) self-esteem, jenis kelamin, neuroticism personality, extraversion personality, dan usia merupakan faktor-faktor yang dapat memberikan pengaruh pada nomophobia. Extraversion menunjukkan tipe kepribadian yang cenderung mempunyai sikap ramah serta senang berinteraksi dengan orang lain (Eysenck \& Eysenck, 1991). Namun Bianchi \& Phillips (2005) menambahkan bahwa extraversion akan memiliki resiko mengalami berbagai perilaku adiktif akibat dari kecenderungannya untuk mencari sensasi. Individu extravert umumnya memiliki alasan untuk mencari situasi sosial, wadah untuk mengekspresikan diri dan sebagai sarana untuk menunjukkan eksistensinya secara luas. Sosialisasi merupakan satu ciri extraversion karena mereka biasanya mempunyai lingkaran sosial yang luas.

Menurut Argumosa, Boada, dan Vigil (2017) nomophobia berkaitan dengan kepribadian terutama ekstraversion dan neuroticism memprediksi individu mengalami kecenderungan nomophobia. Kepribadian ekstraversion dan neuroticism sangat terikat dengan smartphone dimana kecemasan tidak menggunakan smartphone menjadi predikator kecenderungan nomophobia. Sementara tipe kepribadian agreeableness, dan conscientiousness tidak memiliki pengaruh dalam memprediksi kecenderungan nomophobia (Okoye, Harry, \& Obikwelu, 2017). Namun Rahmania \& Prastuti (2021) mengatakan bahwa neuroticism, exstraversion, agreeableness, dan openness memiliki hubungan positif signifikan dengan nomophobia. Ekstraversion tinggi mengindikasikan kecemasan, ketakutan dan perilaku penyalahgunaan smartphone. Sementara kepribadian conscientiousness digambarkan sangat berhati-hati, dapat menahan diri untuk menggunakan teknologi apapun, dan dapat mengalihkan perhatian. 
Fenomena nomohobia terutama pada siswa SMA penting untuk dilakukan karena semakin menunjukkan kondisi yang mengkhawatirkan. Mayoritas siswa yang sudah menunjukkan gejala nomohobia akan semakin sulit untuk melakukan terapi diri sendiri. Penelitian ini ingin melihat perbedaan tingkatan kecenderungan nomophobia pada setiap jenis tipe keribadian openness to experience, conscientiousness, ekstrovert, aggreableness, dan neoriticism. Hasil dari penelitian ini nantinya diharapkan dapat memberikan informasi mengenai ciri-ciri tipe kepribadian yang memiliki kerentanan untuk mengalami kecenderungan nomophobia.

\section{Metode Penelitian}

Penelitian ini menggunakan metode kuantitatif komparatif dengan tujuan ingin membandingkan bagaimana kecederungan nomophobia dari tipe kepribadian yang ada. Pemilihan sampel dilakukan dengan menggunakan teknik sampel proposional. Sampel yang digunakan dalam penelitian ini berjumlah 320 responden siswa SMA dari beberapa sekolah di Kota Bukittinggi yang terdiri dari 117 laki-laki dan 203 perempuan. Pengolahan data menggunakan analisis data one-way-anova dengan bantuan SPSS 16 untuk menguji perbedaan dari satu variabel bebas yang memiliki tiga kelompok data atau lebih.

Instrumen penelitian yang digunakan dalam penelitian ini adalah kuisioner kecenderungan nomophobia yang disusun oleh peneliti berdasarkan dimensi perasaan tidak dapat berkomunikasi, kehilangan konektivitas, tidak dapat mengakses informasi dan menyerah pada kenyamanan yang dikemukakan oleh Yildirim (2014) berisi 34 pernyataan. Skala big five personality menggunakan skala dari (Akhtar \& Azwar, 2019) yaitu IPIP (International Personality Item Pool) yang sudah diterjemahkan kedalam Bahasa Indonesia dalam IPIP-BFM-50, terdiri dari 50 pernyataan.

\section{Hasil Penelitian}

Hasil analisis data pertama menampilkan deskripsi data tingkat kecenderungan nomophobia secara keseluruhan.

Tabel 1.

Kategorisasi Kecenderungan Nomophobia $(\mathrm{N}=320)$

\begin{tabular}{ccccc}
\hline \multirow{2}{*}{ No. } & Skor & $\begin{array}{c}\text { Kategorisasi Kecenderungan } \\
\text { Nomophobia }\end{array}$ & \multicolumn{2}{c}{ Subjek } \\
\cline { 4 - 5 } & & Sangat Tinggi & $\mathbf{\Sigma}$ (\%) \\
\hline 2 & $93,5 \leq \mathrm{X} \leq 110,5$ & Tinggi & 186 & $0 \%$ \\
\hline 3 & $76,5<\mathrm{X}<93,5$ & Sedang & 101 & $31,5 \%$ \\
\hline 4 & $64,5<\mathrm{X} \leq 76,5$ & Rendah & 13 & $4,1 \%$ \\
\hline 5 & $\mathrm{X}<64,5$ & Sangat Rendah & 20 & $6,2 \%$ \\
\hline & Total & & 320 & $100 \%$ \\
\hline
\end{tabular}

Siswa SMA dan SMK sederajat di Kota Bukittinggi memiliki kecenderungan nomophobia yang berada dalam kategori tinggi. Dengan kata lain mayoritas subjek ketika dihadapkan dalam kondisi tidak dapat mengakses smartphone mereka merasa cemas dan khawatir.

Selanjutnya tabel 2 menampilkan lima kategorisasi kecenderungan nomophobia berdasarkan tipe kepribadian subjek penelitian, yaitu sangat tinggi, tinggi, sedang, rendah dan sangat rendah. Dari hasil penelitian yang telah dilakukan didapatkan bahwa subjek yang memiliki tipe kepribadian extraversion memiliki tingkat kecenderungan nomophobia 
pada kategori tinggi. Hal ini menunjukkan bahwa kecenderungan nomophobia lebih tampak pada siswa dengan kepribadian yang cukup aktif, enerjik, banyak bicara, berani, dan mudah bergaul. Selanjutnya, kepribadian yang cenderung mengalami nomophobia diikuti oleh agreeableness. Pada subjek dengan tipe kepribadian conscientiousness dan openness to experiences maoritas mereka memiliki tingkat kecenderungan nomophobia pada kategori rendah. Selanjutnya tipe kepribadian neuroticism menunjukan tingkatan kecenderungan nomophobia yang berada pada kategori sedang

Tabel 2

Kecenderungan Nomophobia Berdasarkan Big Five Personality

\begin{tabular}{|c|c|c|c|}
\hline \multirow{2}{*}{$\begin{array}{c}\text { Big Five } \\
\text { Personality }\end{array}$} & \multirow{2}{*}{$\begin{array}{c}\text { Kategorisasi Kecenderungan } \\
\text { Nomophobia }\end{array}$} & \multicolumn{2}{|c|}{ Subjek } \\
\hline & & $F(\Sigma)$ & $\%$ \\
\hline \multirow{5}{*}{$\begin{array}{c}\text { Opennes To } \\
\text { Experience/Intellect }\end{array}$} & Sangat Tinggi & 0 & $0 \%$ \\
\hline & Tinggi & 1 & $2,6 \%$ \\
\hline & Sedang & 12 & $30,8 \%$ \\
\hline & Rendah & 22 & $56,4 \%$ \\
\hline & Sangat Rendah & 4 & $10,2 \%$ \\
\hline Total & & 39 & $100 \%$ \\
\hline \multirow{5}{*}{ Conscientiousness } & Sangat Tinggi & 0 & $0 \%$ \\
\hline & Tinggi & 2 & $1,8 \%$ \\
\hline & Sedang & 37 & $34 \%$ \\
\hline & Rendah & 64 & $58,7 \%$ \\
\hline & Sangat Rendah & 6 & $5,5 \%$ \\
\hline Total & & 109 & $100 \%$ \\
\hline \multirow{5}{*}{ Extraversion } & Sangat Tinggi & 0 & $0 \%$ \\
\hline & Tinggi & 32 & $56,2 \%$ \\
\hline & Sedang & 18 & $31,6 \%$ \\
\hline & Rendah & 7 & $12,2 \%$ \\
\hline & Sangat Rendah & 0 & $0 \%$ \\
\hline Total & & 57 & $100 \%$ \\
\hline \multirow{5}{*}{ Agreeableness } & Sangat Tinggi & 0 & $0 \%$ \\
\hline & Tinggi & 35 & $57,4 \%$ \\
\hline & Sedang & 21 & $34,4 \%$ \\
\hline & Rendah & 2 & $3,3 \%$ \\
\hline & Sangat Rendah & 3 & $4,9 \%$ \\
\hline Total & & 61 & $100 \%$ \\
\hline \multirow{5}{*}{$\begin{array}{c}\text { Neuroticism/ } \\
\text { Emotional Stability }\end{array}$} & Sangat Tinggi & 0 & $0 \%$ \\
\hline & Tinggi & 1 & $1,9 \%$ \\
\hline & Sedang & 33 & $61,1 \%$ \\
\hline & Rendah & 15 & 27,8 \\
\hline & Sangat Rendah & 5 & 9,2 \\
\hline Total & & 54 & $100 \%$ \\
\hline Jumlah & & 320 & $100 \%$ \\
\hline
\end{tabular}

Sebelum dilakukan uji one-way-anova data diuji normalitas dan homogenitasnya terlebih dahulu. Adapun tujuannya untuk meyakinkan penyebaran data berada pada kondisi normal dan data dalam penelitian ini bersifat homogen. Table 3 menunjukkan hasil uji normalitas data variabel kecenderungan nomophobia dengan nilai $\mathrm{p}=0,125$ $(\mathrm{p}>0,05)$. Selanjutnya pada variabel big five personality memiliki nilai $\mathrm{p}=0,152(\mathrm{p}>0,05)$. Hal ini menunjukkan bahwa data pada kedua variabel terdistribusi secara normal.

Tabel 3.

Hasil Uji Normalitas Sebaran Big Five Personality dan Kecenderungan Nomophobia

\begin{tabular}{lccc}
\hline \multicolumn{1}{c}{ Variabel } & K-SZ & P & Keterangan \\
\hline Kecenderungan Nomophobia & 1,177 & 0,125 & Normal \\
\hline Big Five Personality & 1,135 & 0,152 & Normal \\
\hline
\end{tabular}


Selanjutnya uji homogenitas diperoleh nilai $p=0,656(p>0,05)$. Dengan kata lain data dalam penelitian ini bersifat homogen.

Tabel 4.

Hasil Uji Homogenitas Big Five Personality

\begin{tabular}{ccccc}
\hline Levene Statistic & df1 & df2 & Sig. & Keterangan \\
\hline 0,610 & 4 & 315 & 0,656 & Homogen \\
\hline
\end{tabular}

Adapun untuk menjawab pertanyaan penelitian ini adalah berdasarkan hasil uji one-way-anova diperoleh nilai signifikansi Sig. $=0,038$ (Sig.<0,05). Hal tersebut menunjukkan bahwa terdapat perbedaan kecenderungan nomophobia ditinjau dari big five personality.

Tabel 5.

Hasil Uji Hipotesis

\begin{tabular}{lcc}
\hline \multicolumn{1}{c}{ Kecenderungan Nomophobia } & F & Sig. \\
\hline $\begin{array}{l}\text { Kecenderungan Nomophobia } \\
\text { Berdasarkan Big Five Personality }\end{array}$ & 2,566 & 0,038 \\
\hline
\end{tabular}

\section{Pembahasan}

Hasil penelitian menunjukkan bahwa terdapat perbedaan kecenderungan nomophobia ditinjau dari big five personality pada siswa SMA dan SMK Sederajat di Kota Bukittinggi. Dengan kata lain memang ada perbedaan kecenderungan nomophobia pada setiap tipe kepribadian berbeda. Hal ini sejalan dengan penelitian terdahulu yang menunjukkan bahwa kepribadian menjadi prediktor dari kecenderungan nomophobia (Argumosa-Villar, Boada-Grau, \& Vigil-Colet, 2017; Bianchi \& Philips, 2005; Rahmania \& Prastuti, 2021). Selanjutnya kecenderungan nomophobia juga dapat dilihat berdasarkan tipe kepribadian. Berdasarkan hasil penelitian yang diperoleh, siswa dengan kepribadian extraversion merupakan pribadi yang lebih cenderung mengalami nomophobia. Hal yang sama juga dikatakan oleh penelitian sebelumnya yang mengemukakan bahwa tipe kepribadian extraversion memprediksi nomophobia secara signifikan (Argumosa-Villar, Boada-Grau, \& Vigil-Colet, 2017; Okoye, Harry, \& Obikwelu, 2017).

McCrae dan Costa (2003) menjelaskan bahwa individu dengan kepribadian extraversion merupakan pribadi yang aktif, sering berbicara, berenergi, mudah bergaul dan menyukai kesenangan Lebih lanjut, pribadi extraversion sebagai individu yang cenderung memiliki nomophobia digambarkan melalui kecenderungan dalam menghabiskan waktu yang lebih banyak untuk menikmati serta mempertahankan hubungan dengan orang lain. Hal tersebut membuat kepribadian extraversion lebih rentan mengalami kecenderungan nomophobia, karena pada dasarnya individu dengan tipe kepribadian extraversion tinggi memiliki kebutuhan untuk terlibat dalam situasi sosial termasuk smartphone (Bianchi \& Phillips, 2005).

Sosiabilitas merupakan ciri utama tipe kepribadian extraversion dengan konsekuensi cenderung memiliki lingkaran pertemanan dan jaringan sosial yang lebih besar. Hal ini mendorong individu dengan tipe kepribadian extraversion untuk tetap mempertahankan hubungan dengan banyak orang secara luas melalui pesan singkat, video call dan memainkan smartphone. Mereka bahkan tetap menggunakan smartphonenya di tempat yang dilarang penggunaannya seperti pom bensin, toilet, dan pesawat, sehingga perilaku ini dapat mengarah kepada kecenderungan nomophobia (Bianchi \& Phillips, 2005).

Hasil penelitian juga menunjukkan bahwa agreeableness juga berpotensi menimbulkan nomophobia. Hasil penelitian ini bertolak belakang dengan penelitian 
terdahulu yang menjelaskan bahwa kepribadian agreeableness tidak terlalu berkaitan secara signifikan terhadap nomophobia, karena pribadi agreeableness tidak rentan terhadap kecemasan irasional, khususnya terhadap smartphone (Okoye, Harry, \& Obikwelu, 2020). McCrae dan Costa (2003) menyatakan individu dengan skor agreeableness tinggi digambarkan sebagai individu yang ramah, penuh kasih sayang, toleran, dermawan. Sementara pada individu dengan skor rendah digambarkan sebagai individu yang memliki interaksi sosial yang buruk didunia nyata, sehingga menyadari orang lain membuat jarak, tidak adanya kedekatan dan memotivasi individu untuk mencari kontak sosial didalam smartphone yang dapat mengarah pada perilaku kecenderungan nomophobia.

Individu dengan tipe kepribadian conscientiousness merupakan pribadi yang terorganisir, tekun, tepat waktu, efisien dalam melakukan pekerjaan dan sistematis (McCrae \& Costa 2003). Lebih lanjut, pribadi dengan conscientiousness rendah digambarkan sebagai pribadi yang ceroboh tidak konsisten dan lalai, tidak peduli dengan perencanaan, kemudian pribadi ini lebih tertarik dengan smartphone sehingga dapat mengarahkan kepada perilaku kecenderungan nomophobia karena terlalu asyik bersama smartphone sehingga tidak memperhatikan tugas di kehidupan sehari- hari (Abraham, Mathias \& Williams, 2014).

Individu dengan tipe kepribadian neuroticism digambarkan sebagai pribadi yang cenderung sensitif, mudah cemas, gugup, dan tegang (McCrae \& Costa 2003). Kemudian pribadi dengan tipe kepribadian neuroticism menggunakan smartphone secara berlebihan akan menyebabkan orang dengan tipe kepribadian ini mudah merasa cemas ketika tidak dapat mengakses informasi melalui smartphonenya dan pada saat mengirim pesan atau email, ketika tidak segera mendapatkan balasan dari pesan atau email yang dikirim membuat pribadi ini merasa khawatir dan mudah cemas (Bianchi \& Phillips, 2005).

Tipe kepribadian terakhir yang menjadi prediktor terhadap kecenderungan nomophobia pada subjek penelitian ini ialah openness to experience/intellect. Hasil ini bertolak belakang dengan temuan Okoye, Harry dan Obikwelu, (2020) yang menunjukkan bahwa openness to experience/intellect mempengaruhi nomophobia secara signifikan. Pribadi openness to experience/intellect dengan kecenderungan nomophobia digambarkan sebagai individu yang tidak kreatif dan konvensional, sehingga mereka tidak mencari kegiatan lain, melainkan tetap pada perilaku bermain smartphone yang mengarah pada perilaku kecenderungan nomophobia (Ariana \& Prasetyo, 2016). Bertolak belakangnya hasil penelitian saat ini dengan sebelumnya dikarenakan mayoritas subjek pada penelitian ini memiliki skor openness to experience/intellect yang tinggi dimana subjek merupakan pribadi yang intelektual aktif dan berpikiran terbuka, kreatif, introspektif, memiliki imajinasi yang hidup, serta memiliki beragam minat.

Selain penjabaran mengenai bagaimana masing-masing tipe kepribadian mempengaruhi nomophobia, diperoleh juga hasil mengenai kategori nomophobia pada subjek penelitian. Perolehan hasil penelitian menunjukkan bahwa kecenderungan nomophobia pada siswa SMA dan SMK sederajat di Kota Bukittinggi secara umum berada pada kategori tinggi, artinya subjek penelitian merasa cemas dan khawatir ketika tidak dapat mengakses smartphone. Akhirnya, dominasinya subjek pada kategori tinggi terkait kecenderungan nomophobia perlu diwaspadai karena nomophobia tidak lepas dari perasaan cemas dan khawatir yang dirasakan pada subjek penelitian, khususnya ketika tidak dapat mengakses smartphone (Kuscu, Gumustas, Rodopman Arman, \& Goksu, 2021).

\section{Simpulan dan Saran}

Hasil penelitian ini menunjukkan adanya perbedaan kecenderungan nomophobia ditinjau dari big five personality. Selain itu mayoritas subjek berada pada kategori tinggi untuk mengalami kecenderungan nomophobia. Jenis kepribadian subjek didominasi oleh 
tipe kepribadian conscientiousness, agreeableness, neuroticism/ emotional stability, dan terakhir extraversion, dan opennes to experience/ intellect. Kepribadian yang memiliki kerentanan untuk mengalami kecenderungan nomophobia membutuhkan pengontrolan terhadap diri sendiri. Selain itu implikasi dari temuan ini adalah bagi orang tua dapat lebih mengawasi anaknya dalam penggunaan smartphone. Untuk penelitian selanjutnya disarankan dapat meninjau variable lain yang dapat mempengaruhi kecenderungan nomophobia.

\section{Daftar Pustaka}

Abraham, N., Mathias, J., \& Williams. S. (2014). A study to assess the knowledge and effect of nomophobia among students of selected degree college in Mysore. Asian Journal of Nursing Education and Research 4(4), 421-428. http://dx.doi.org/10.5958/2454-2660.2019.00075.9

Aggarwal, M., Basu, D., \& Grover, S. (2012). Mobile phone use by resident doctor: Tendecy to addiction-like behaviour. German Journal of Psychiatry, 15(2) 50-55

Argumosa-Villar, L., Boada-Grau, J., \& Vigil-Colet, A. (2017). Exploratory investigation of theoretical predictors of nomophobia using the Mobile Phone Involvement Questionnaire (MPIQ).Journal of Adolescence, 56, 127-135. https://dx.doi.org/10.1016/j.adolescence.2017.02.003

Bianchi, A., \& Phillips, J. G. (2005). Psychological predictors of problem mobile phone use. Cyber Psychology \& Behavior, 8(1), 39-52

Bragazzi, N. L., \& Puente, G. D. (2014). A proposal for including nomophobia in the new DSM-V. Psychology Research and Behavior Management, 7, 155-160. https://dx.doi.org/10.2147/PRBM.S41386

Febriana, C., \& Mariyana (2020). Hubungan karakteristik remaja dengan tingkat kecanduan gadget dikota bukittinggi. Real in Nursing Journal, 3(3), 174- 183. http://dx.doi.org/10.32883/rnj.v3i3.1054.g404

King, A. L. S., Valenca, A. M., \& Nardi, A. E. (2010). Nomophobia: The mobile phone in panic disorder with agoraphobia reducing phobias or worsening of dependence?. Cognitive and Behavioral Neurology, 23(1). 52-54. http://dx.doi.org/10.1097/WNN.0b013e3181b7eabc

King, A. L. S., Valenca, A. M., Silva, ACO., Baczynski, T., Carvalho, M. R., \& Nardi, A. E. (2013). Nomophobia: Dependency on virtual environments or social phobia?. Computers in Human Behavior 29(1). 140-144. https://dx.doi.org/10.1016/j.chb.2012.07.025

McCrae, R. R., \& Costa, P. T. (2006). Personality in Adulthood Second Edition A Five-Factor Theory Perspective. New York: The Guilford Press

Nasution, J. A., Neviyarni, S., \& Alizamar. (2017). Motif siswa menggunakan smartphone dan penggunaannya. Jurnal Penelitian Pendidikan Indonesia, 3(2), 15-29. https://dx.doi.org/10.29210/02017114

Okoye, C. A. F., Harry, H. O. N., \& Obikwelu, V. C. (2017). Nomophobia among undergraduate: Predictive influence of personality trait. Practicum Psikologia, $7(2), 64-74$

Prasetyo, A., \& Ariana, A. D. (2016). Hubungan antara the big five personality dengan nomophobia pada wanita dewasa awal. Jurnal Psikologi Klinis dan Kesehatan Mental, 5(1), 1-9.

Rahmania, D. B., \& Prastuti, E. (2021. Peran dimensi kepribadian terhadap nomophobia mahasiswa. Jurnal Sains Psikologi, 3(1). 9-20

Villar, L. A., Grau, J. B., \& Colet, A. V. (2017). Exploratory investigation of theoretical predictor of nomophobia using the mobile phone involvement questionnaire $\begin{array}{lllll}\text { (MPIQ). Journal of } & \text { Adolescence, 56, }\end{array}$ https://dx.doi.org/10.1016/j.adolescence.2017.02.003 
Yildirim, C. (2014). Exploring the dimensions of nomophobia: Developing and validating a questionnaire using mixed methods research. Graduate Theses and Dissertations, 1102.

Yulman. (2018). Kehadiran taman digital menunjang program bukittinggi smart city. Retrieved Maret 6, 2021 from http://bukittinggikota.go.id/berita/kehadirantaman-digital-menunjang-program-bukittinggi-smart-city

Yuwanto, L. (2010). Mobile phone addict. Retrieved Oktober 26, 2020 from https://www.ubaya.ac.id/2018/content/articles detail/10/Mobile-Phone-Ad \dict.html 